\title{
LA NOVELA MODERNISTA HISPANOAMERICANA Y LAA LITERATURA EUROPEA DE FIN DE SIGLO: PUNTOS DE CONTACTO Y DIFERENCIAS
}

Es preciso examinar la novela modernista hispanoamericana en el marco de las condiciones tanto literarias como socio-económicas y políticas que contribuyeron a la aparición y al desarrollo del modernismo en las letras hispánicas. Los rasgos particulares que distinguen este tipo de novela de sus precursores sólo se explican plenamente sobre el trasfondo de las diferentes condiciones que los originaron. Sigo llamando "modernismo" al conocido movimiento literario hispánico de este nombre por razones de conveniencia, a pesar de los distintos significados que se suele atribuir al concepto". En otro lugar, he tratado de completar la denominación de "modernismo" por la de "literatura de lin de siglo", con la cual comparte algunas particularidades de orden históricoliterario ${ }^{2}$. Era ésta una tentativa de precisar el uso del concepto, evitando las desventajas de su vaguedad. Es obvio que, por más que sea susceptible de diversas interpretaciones, no podemos prescindir de la

${ }^{1}$ Existe una investigación especial acerca del significado del término "modernismo" y su extensión; cf. los resúmenes de NED DAVISON, El concepto de modernismo en la crítica hispánica, trad. de J. Hancock, Nova, Buenos Aires, 1971, y AnTonio Melis, "Bilancio degli studi sul modernismo ispanoamericano", en Lavori ispanistici, Firenze, 1970, pp. 257-312; cf. además los trabajos recientes de G. Siebenmann, "Modernismos y vanguardia en el mundo ibérico', $A L M, 20$ (1982), 251-286, y A. A. RogGIANO, "Modernismo: origen de la palabra y evolución de un concepto", en $H B C$, pp. 93103. Acerca de la denominación de "decadentismo" y "decadente" que es anterior a la acuñación del término "modernismo" en Hispanoamérica y que, durante algunos años, se usa como sinónimo de este último, véase el trabajo de J. Olivares, "La recepción del decadentismo en Hispanoamérica', $H R$, 48 (1980), 57-76, y las observaciones de A. W. Phillips, "A propósito del decadentismo en América: Rubén Darío", $R C E H, 1$ (1977), 229-254.

${ }^{2}$ Cf. Klaus Meyer-Minnemann, Der spanischamerikanische Roman "des fin de siècle', M. Niemeyer, Tübingen, 1979, pp. 7 ss. 
palabra "modernismo" para el estudio de la historia de las letras hispánicas a fines del siglo XIx, puesto que ya pertenece al lenguaje de la crítica literaria. Por otra parte resulta necesario especificar, por lo menos brevemente, la acepción de la palabra y su extensión, cada vez que se quiera hacer uso de ella. En adelante, daré el nombre de "modernismo" (o sea de "modernista") al movimiento literario hispanoamericano dominante que como generador de normas literarias floreció entre 1888 y 1910 aproximadamente. Visto en el nivel de la evolución literaria pura y simple, este movimiento se estableció en franca oposición tanto a las normas literarias del mundo hispánico de su epocá (representadas en las normas custodiadas por la Real Academia Española ${ }^{3}$ ) como al naturalismo europeo con sus pretensiones cientificas positivistas. Empezó a llamarse "modernismo" a partir de los año noventa por insinuación y obra especialmente de Rubén Dario

En su totalidad, el modemismo representa la modalidad hispánica de aquella literatura europea postenior al naturalismo que hizo suyo (entre otros) el nombre de "fin de siècle"5. Sabemos que este último se acuñó, al principio, para caricaturizar a la recién nacida corriente antinaturalista en las letras ${ }^{6}$. Los autores de la nueva fórmula adoptaron este letrero para afirmar despectivamente su posición aristocratizante frente a la sociedad burguesa de su época.

El modernismo hispanoamericano escogió como punto de orientación los procedimientos y actitudes de la literatura europea finisecular, que había conocido a través de la divulgación francesa. Hay que añadir, sin embargo, que no los escogió para realizar las mismas intenciones. En efecto, gracias a las investigaciones de Valentí i Fiol, Marfany y otros acerca del modernismo catalán (el que, casi sin tener puntos de contacto directo, ofrece un parentesco estructural con el movimiento modernista hispanoamericano), sabemos que en zonas culturales periféricas respecto al centro - que en esa época, culturalmente hablando es París - los movimientos artísticos de vanguardia no suelen adoptar los procedimientos y actitudes de las vanguardias vigentes por los contenidos que encierran, sino por el carácter de modernidad que

3 La Real Academia no sólo vigilaba las normas literarias en España sino también en Hispanoamérica; cf. KLAus Scherag, Die spanischamerikanische Literatur in der Kritik des 19. Jahrihunderts, tesis, Univ. de Bonn, 1966, esp. pp. 36 ss., así como C. RAMA, La historia de las relaciones culturales entre España y la América, Madrid, 1982.

${ }^{4}$ Cf. A. W. Phillips, "Rubén Darío y sus juicios sobre el modernismo", Revlb, 24 (1959), 41-64; E. Uhrhan IRVING, "Rubén Darío's first days in Guatemala", $H$, 46 (1963), 319-322; M. HoRÁNYI, "Notas sobre el concepto de modernidad de Rubén Darío", RChL, 2/3 (1970), 199-206.

5 Acerca de la denominación "fin de siècle" y los estudios al respecto, cf. mi trabajo "Einige neuere Darstellungen des fin de siècle", RJ, 30 (1979), 112-126, esp. pp. 112-114.

${ }^{6}$ Cf. K. G. Millward, L'oeuvre de Pierre Loti et l'esprit 'fin de siècle", Paris, 1955, pp. 11 ss. 
prometen ${ }^{7}$. Siendo así, no es de extrañar que estos movimientos artísticos en zonas de periferia hayan mostrado una marcada tendencia a llamarse "modernos", de acuerdo con sus intenciones más íntimas de participación en la modernidad de su época. Es éste el caso del modernismo catalán y del modernismo hispanoamericano. Hubiera podido ser también el caso del modernismo español, de no haber existido el contacto directo con la literatura hispanoamericana que hizo del modernismo en España un artículo, muy discutido, de importación desde la periferia y dentro de ella ${ }^{8}$.

Para comprender bien el porqué de la orientación hacia la literatura de fin de siglo, orientación que caracteriza al modernismo hispanoamericano, es preciso tener en cuenta el momento histórico de su aparición. El modernismo hispanoamericano surge cuando algunas regiones latinoamericanas, precisamente las más avanzadas desde el punto de vista económico, entran de lleno en el círculo internacional de producción y distribución capitalistas en la segunda mitad del siglo XIX. Estas regiones, en primer lugar el Río de la Plata, ejercen, por su incipiente civilización urbana moderna, su aparente prosperidad y sus promesas para el futuro, una fuerte influencia sobre la vida y la conciencia culturales del continente.

7 Sobre el surgimiento del concepto de "lo moderno" y de una literatura de la modernidad, cf. H. R. JAuss, "Literarische Tradition und gegenwärtiges Bewusstsein der Modernität"', en Literaturgeschichte als Provokation, Frankfurt, 1970, pp. 11-66; A. MARINO, "Modernisme et modernité, quelques précisions sémantiques", Neoh, 2 (1974), 307-318; Matei Calinescu, Faces of modernity: Avant-garde, decadence, kitsch, Indiana Umversity Press, Bloomington-London, 1977.

${ }^{8}$ Cf. Eduard VAlentí I FIOL, El primer modernismo literario catalán y sus fundamentos ideológicos, Ariel, Barcelona, 1973; JOAN-Lluis MaRrany, Aspectes del modernisme, Barcelona, 1975, especialmente la sección intitulada "Sobre el moviment modernista", pp. 11-96. Al basarme en los trabajos de VALENTí i FIOL y MARFANY para aclarar el carácter de los lazos entre producción literaria (modernismo) y condiciones socioeconómicas en Latinoamérica a finales del siglo XIX, discrepo del modelo de explicación isomórfico de ÁNGel RAMA, Rubén Darío y el modernismo (circunstancia socioeconómica de un arte americano), Universidad Central de Venezuela, Caracas, 1970, que ya ha sido criticado por FrançoIse Perus, Literatura y sociedad en América Latina, Siglo XXI, México 1976 , pp. 65 ss. A pesar del avance que marca el estudio de Perus sobre el isomorfismo del desarrollo socio-económico y cultural en Europa y Latinoamérica que postula RAMA, su trabajo adolece (amén de otros puntos débiles, especialmente en cuanto a las técnicas del análisis de textos literarios) de una falta de incorporación de perspectiva hacia el público enfocado, falta que observamos en casi la totalidad de los estudios histórico-sociales hasta fechas todavía muy recientes. En un artículo polémico y brillante J.-Ll. MARFANY ("Algunas consideraciones sobre el modernismo hispanoamericano", $C u H, 1982$, núm. 382, 82-124) ha replanteado los problemas de una historia social del modernismo, haciendo hincapié en la insuficiencia de las respuestas dadas hasta ahora, tanto por los representantes de la definición del modernismo con base en un esteticismo del contenido, como por los representantes del concepto de época o, también, del consenso general, en el sentido de las clasificaciones de N. DAVISON, (op. cit). MARFANY se muestra en sus planteamientos y postulados mucho más sistemático y riguroso que Rafael Gutiérrez Girardot en su ensayo polémico, Modernismo, Montesinos, Barcelona, 1983. 
Marcan el momento de la formación de una nueva clase media latinoamericana que parece reclamar una literatura que esté a la altura de su propia modernidad. Esta literatura pretende ser el modernismo hispanoamericano. Lo pretende a pesar de algunas peculiaridades de su punto de referencia europeo. Efectivamente, en la respuesta de los autores modernistas a la expectativa cultural de su tiempo, respuesta motivada por la experiencia, aún vaga, de una nueva etapa del desarrollo socioeconómico en Latinoamérica, se da la paradoja de que la orientación hacia la vanguardia literaria del centro cultural parisiense - orientación que no hace más que reproducir, en el nivel cultural, la orientación económica de las regiones latinoamericanas mencionadas- con. duzca a la adopción mutatis mutandis de una literatura que, por su parte, declara abiertamente estar en oposición a la sociedad burguesa de su época. Esto significa que el modernismo hispanoamericano, con el fin de responder literariamente a la modernidad y a la expectativa del momento, se sirve de procedimientos y actitudes que, en su área de origen, funcionan como antítesis declarada del mundo económico y político-social que los rodea. Es verdad que no los adopta en vista de sus contenidos sino en virtud de su carácter de modernos. Pero no puede dejar de sostener algunas de las actitudes más características del fin de siglo europeo, y, por lo tanto, hacerse responsable de ellas. Ha escogido el fin de siglo europeo como punto de orientación y garantía de sus propias intenciones de modernidad, y al hacerlo ha aceptado también los rasgos distintivos de sus componentes. Así se explican, para citar un solo ejemplo, las declaraciones contra la época (con el fin de connotar, gracias a ellas, la propia modernidad) que caracterizan las palabras preliminares de Prosas profanas ${ }^{9}$.

Se sabe que el género literario predilecto del modernismo no es la novela. El fin de siglo europeo, especialmente en sus reflexiones teóricas, desconfiaba de la novela porque había sido el género preferido de las pretensiones naturalistas ${ }^{10}$. Si bien se puede apreciar una tendencia hacia otros géneros narrativos, no es menos cierto que muchas veces se desecharon a favor del poema en prosa y de la poesía. Había autores, sin embargo, que seguían con la novela, proponiendo transformarla de tal manera que pudiera cuadrar con las aspiraciones antinaturalistas del fin de siglo. Baste con mencionar los nombres de Huysmans, Rémy de Gourmont, Henri de Régnier o D'Annunzio, el más llamativo de todos, para dar una idea de aquella novelística. Los modernistas hispanoamericanos que, por lo general, escogieron el género novelístico como uno entre muchos, seguían, cada cual dentro de su propia predilección, la pauta europea.

9 Cf. Rubén Darío, Prosas profanas; "Palabras liminares", en Poesías completas, eds. A. Méndez Plancarte y A. Oliver Belmás, $10^{\text {a }}$ ed., Madrid, 1967, pp. 545-547.

${ }^{10}$ Cf. Michel Raimond, La crise du roman. Des lendemains du naturalisme aux années vingt, José Corti, Paris, 1966, pp. 25-84. 
Tomada en su conjunto, la novela modernista hispanoamericana se caracterizó por los siguientes rasgos generales:

En el plano del contenido:

- La oposición entre el sistema de valores del protagonista y su medio ambiente.

- La ostentación, por parte del protagonista, de un vanguardismo literario, artístico o sencillamente cultural, en función de protesta contra este medio ambiente.

- La posibilidad de relacionar el medio ambiente del texto de ficción con la realidad contemporánea latinoamericana, sea por medio de un mundo que represente esta realidad, o sea por medio de un mundo histórica y/o geográficamente alejado, pero, por lo general, en alguna relación reconocible con la realidad latinoamericana del momento.

En el plano de la expresión:

- La concentración del argumento a favor del protagonista con enfoque particular en las vicisitudes de su "vida interior" (sensaciones y sentimientos).

- El empleo consciente de los medios de expresión, especialmente del estilo indirecto libre, para la representación de esta "vida interior".

- El desarrollo de un léxico y de una sintaxis apropiados, en contra de las normas oratorias vigentes de la prosa literaria hispana, para establecer un paralelo a la ostentación del vanguardismo literario, artístico o cultural del protagonista.

Dentro de estos rasgos, cada novela significa una realización única de la orientación general. Frecuentemente, en una obra determinada, no encontramos todos los rasgos del modelo con la misma nitidez. La ausencia parcial o el poco desarrollo de un rasgo no es prueba de la validez dudosa del concepto. Hay que tener en cuenta que cuando empleamos nociones como "la novela modernista", nos referimos a una abstracción más o menos explícitamente asentada sobre una visión de conjunto. Comparada con ella, la obra singular sólo representa un ejemplar —en cuya composición, además, entran a veces otros elementos- del modelo general que se desprende de la visión de conjunto. En este sentido es lícito emplear un panorama sintetizador para poder determinar en qué respecto un determinado corpus literario que, además, tiene conciencia de sí mismo, se distingue de otro corpus (en este caso tanto la novela naturalista como la narrativa hispánica del romanticismo y del realismo), con el cual quiere hacer contraste. Es lícito también cuando se mantenga una perspectiva histórica que sitúe el objeto literario en el conjunto del contexto económico y político-social de la época que lo engendró.

Comparte la novela modernista hispanoamericana los rasgos indicados con la novela del fin de siglo europeo. Pero los comparte de una manera especial. El medio ambiente que pretende representar es diferente del que representa la novela finisecular europea. Puede ser un medio ambiente latinoamericano. Entonces se trata de una transposición de la realidad novelística usual en la novela del fin de siglo europeo, con 
miras a un público hispanoamericano. Este medio ambiente, en su función hostil para el protagonista, resulta ser la versión latinoamericana del medio ambiente correspondiente de la novela europea. Así sucede, por ejemplo, en El extraño de Carlos Reyles o en Ídolos rotos de Díaz Rodríguez ${ }^{11}$.

Pero a veces encontramos la misma realidad novelística que conocemos de las novelas europeas. En estos casos, como sucede en De sobremesa de José Asunción Silva, en La tristeza voluptuosa de Pedro César Dominici, o en las novelas de Enrique Gómez Carrillo ${ }^{12}$, el medio ambiente representado lleva una nota de exotismo que le es totalmente ajeno a su punto de referencia europeo. La novela finisecular europea sólo lleva esta nota de exotismo cuando sitúa su argumento en un mundo geográficamente fabuloso como ol Oriente, o cuando elige una realidad de pasado histórico (a veces también mítico). Este mundo novelístico guarda su cualidad de exótico cuando se presenta a un público hispanoamericano. Ejemplos de esta corriente ofrecen La Reina de Rapa Nui de Peciro Prado $^{13}$, la que, por llegar relativamente tarde, ya muestra un mundo novelesco de tradiciones juzgadas autóctonas ${ }^{14}$, o las novelas Nikko y Hojas de bambú del escritor mexicano Efrén Rebolledo ${ }^{15}$. En el campo de la novela histórica basta citar el ejemplo de las novelas truncadas de Rubén Darío - me refiero a El hombre de oro- y de Ricardo Jaimes Freyre $^{16}$, o las novelas de Emilio Cuervo Márquez (Phinées. Tragedia de los tiempos de Cristo) y de Pedro César Dominici (Dionysos. Costumbres de la Antigua Grecia) ${ }^{17}$. En estos ejemplos, las posibilidades de establecer alguna relación directa entre el mundo novelesco y la realidad iatino-

11 Cf. Carlos Reyles, El extraño (Academias), Madrid, 1897; Manuel Díaz Rodríguez, ídolos rotos, París, 1901. Como todavía faltan ediciones críticas, daré en adelante el lugar y la fecha de la primera edición, añadiendo la edición utilizada cuando no se trate de ésta.

12 A raíz del suicidio de José Asunción Silva en mayo de 1896, la novela De sobremesa quedó sin edición hasta 1925, cf. José Asunción Silva, De sobremesa, Bogotá, 1925 (ed. utilizada: Obras completas, eds. A. Miramón y C. de Brigard Silva, Bogotá, 1965, pp. 123-310); Pedro CÉSAR Dominici, La tristeza voluptuosa, Madrid, 1899; EnriQue Gómez Carrillo, Del amor, del dolor y del vicio, Madrid, 1898 (ed. utilizada: París, 1901, con un prólogo de Rubén Darío); Bohemia sentimental, s.1., 1899; Maravillas, Madrid, 1899 (ed. utilizada: París-México, 1906).

${ }^{13}$ Cf. Pedro Prado, La reina de Rapa Nui, Santiago (Chile), 1914 (ed. utilizada: Santiago, Chile, 1962).

${ }^{14}$ En esta misma línea se sitúan los cuentos incaicos de Abraham Valdelomar; cf. la edición Los hijos del Sol. Cuentos incaicos, Ciudad de los Reyes (Lima), 1921.

15 Cf. Efrén Rebolledo, Nikko, México, 1910; Hojas de bambú, ibid. (ed. utilizada: Obras completas, ed. L. M. Schneider, México, 1968).

16 Cf. RubÉn Darío, El hombre de oro, La Biblioteca, 4 (1897), 247-261 y 384-396; ibid., 5 (1897), 433-442; acerca del ensayo novelístico de Jaimes Freyre, cf. E. CARILLA, "Jaimes Freyre, cuentista y novelista", BICC, 16 (1961), 664-698.

17 Cf. Emilio Cuervo Márquez, Phinées. Tragedia de los tiempos de Cristo, Bogotá, 1909 (ed. utilizada: París, s.f.); Pedro César Dominici, Dionysos. Costumbres de la antigua Grecia, París, 1904 (ed. utilizada: París, 1905). 
americana del momento son nulas, lo que no impide que pertenezcan a la orientación finisecular. Por el contrario, se da la paradoja de que el exotismo del contenido garantice las aspiraciones de modernidad de estas obras con respecto al público enfocado.

El caso de La gloria de don Ramiro, la novela histórica más famosa del modernismo hispanoamericano, es más complicado ${ }^{18}$. En esta novela de Larreta, el mundo novelesco, de acuerdo con la conciencia renovada de la hispanidad de América (conciencia despertada por la guerra de 1898 y la experiencia del creciente imperialismo norteamericano), quiere evocar (en una orientación ideológica claramente reconocible) la supuesta raíz común de todos los países hispanoamericanos. Es ésta la razón por la cual, al final de la obra, se le revela su verdadera. glona d protagonista, después del encientrocon la santa de Lima, en su autosacrificio por un indio enfermo. Por otra parte, este mismo mundo novelesco, el tiempo de Felipe II, funciona como medio ambiente hostil para un protagonista que nunca llega a la plena conciencia de ello. Resulta necesario distinguir tres capas de significación en la realidad novelística de La gloria de don Ramiro. Lleva una nota de exotismo con respecto al público enfocado por representar una España lejana, la del siglo XVI. Al mismo tiempo quiere evocar un pasado y una tradición comunes que, en el enfoque del autor implícito, es preciso actualizar. Finalmente, en cuanto al protagonista y sus aspiraciones, funciona como medio ambiente hostil ${ }^{19}$.

Bastante interesantes son las obras en las cuales la realidad novelística representa un aspecto típico de la situación latinoamericana del momento. Me refiero a esas novelas que, por lo menos en parte, hacen del buque transatlántico que asegura el intercambio entre centro y periferia (por cierto, mucho más importante para ciertas capas sociales de la periferia que para el centro) el escenario de la acción. Éste es el caso de Sangre patricia de Díaz Rodríguez y de La ilusión del argentino Ángel de Estrada ${ }^{20}$.

El rasgo diferencial de la oposición entre el sistema de valores que proclama el protagonista de la novela modernista y su medio ambiente, tiene por consecuencia el intento de crear un mundo autónomo particular, en el cual ya no puede interferir la abominada realidad. El modelo más llamativo de este mundo aparte, que encontramos en la casa de Julio Guzmán en El extraño, o en el palacio de don Alonso en La gloria de don Ramiro, era la tebaida de Fontenay-aux-Roses. Por lo extremoso

18 Cf. Enrigue Larreta, La gloria de don Ramiro. Una vida en tiempos de Felipe II, Madrid, 1908.

${ }^{19}$ El estudio más valioso sobre la novela de Larreta sigue siendo el conocido trabajo de Amado Alonso, Ensayo sobre la novela histórica. El modernismo en "La gloria de don Ramiro", Instituto de Filología, Buenos Aires, 1942; véase ademâs la monografia de A. JANSEN, Enrique Larreta, novelista hispano-argentino, Madrid, 1967.

20 Cf. Manuel Díaz Rodríguez, Sangre patricia, Caracas, 1902 (ed. utilizada: Madrid, s.f.); ÁNGEL DE EstradA, La ilusión, Buenos Aires, 1910. 
de su concepción, inspirada en los paisajes y decoraciones antinaturalistas de Baudelaire, el sumo poeta del fin de siglo incipiente, la invención de Huysmans influyó en la casi totalidad de los antimundos artificiales del modernismo. Notamos las huellas de $\dot{A}$ rebours, amén de las obras ya mencionadas, en las habitaciones de José Fernández en De sobremesa, o también en la descripción del nido amoroso de Viviana, la protagonista de Del amor, del dolor y del vicio de Enrique Gómez Carrillo ${ }^{21}$. A esta lista se podría añadir el taller de Alberto Soria en Ídolos rotos. Este taller ya significa un paso hacia adelante en cuanto a la función del antimundo finisecular en la novela modernista hispanoamericana. Se opone a una cierta realidad urbana de Latinoamérica alrededor de 1900 (la ciudad de Caracas precisamente ${ }^{22}$ ), que en su afán de modernidad sólo llega a ser una caricatura del modelo imitado. El intento de Alberto Soria de crear un arte latinoamericano que esté al tanto de la entrada de esta parte del mundo en la civilización moderna, fracasa en el momento del estallido de una nueva revolución. Revela, independientemente de la abulia fatal del protagonista, lo frágil de los fundamentos sobre los cuales se basa la supuesta entrada del país en el círculo del mundo "civilizado" 23 (i.e., de los países económica y políticamente hegemónicos). Se sabe que en esta novela de Díaz Rodríguez se encuentra también una advertencia contra el imperialismo norteamericano ${ }^{24}$, después del primer desarrollo novelístico del tema en El problema de Máximo SotoHall ${ }^{25}$. Advertencias de esta índole no existen, claro está, en la novela del fin de siglo europeo.

No siempre se crea un ámbito de artificialidad, una especie de invernadero, para aludir a otro reducto favorito del fin de siglo, en función de protesta contra el medio ambiente hostil. La "otra región" puede ser también una cultura diferente, como el mundo islámico en La gloria de don Ramiro, o el Japón de las novelas de Efrén Rebolledo. Puede ser una cultura desaparecida como la Grecia de Pericles en la novela Dionysos de Pedro César Dominici, un castillo con jardín como en El triunfo del

${ }^{21}$ Cf. E. Gómez Carrillo, op. cit. pp. 68 ss. y mi estudio "Enrique Gómez Carrillo, Del amor, del dolor y del vicio. Anotaciones en torno a una novela del modernismo hispanoamericano", NRFH, 22 (1973), 61-77.

22 El escenario de Ídolos rotos es Caracas (y una estación balnearia cerca de la capital venezolana), a la cual el protagonista vuelve después de años de "estudio" en París.

${ }^{23}$ Revela lo frágil de esos fundamentos en la opinión del protagonista y en la del autor implícito. En realidad, la revolución que pone fin a los proyectos culturales de Alberto y sus amigos corresponde a un estado de cosas en Venezuela, alrededor de 1900 , que pertenece a una etapa todavía anterior a la incorporación del país al sistema económico internacional. Hay una clara diferencia entre la región del Río de la Plata y Venezuela, por ejemplo, en cuanto al desarrollo económico y político-social al final del siglo pasado.

${ }^{24}$ Cf. M. Díaz Rodríguez, op. cit., pp. 348 s.

${ }^{25}$ Cf. Máximo Soto-Hall, El problema, San José (Costa Rica), 1899. Acerca de esta obra, cf. SEYMOUR Menton, 'Historia crítica de la novela guatemalteca, Guatemala, 1960 , pp. $124 s$. 
ideal del mismo autor (según el modelo d'annunziano de Le Vergini delle Rocce $^{26}$, o sencillamente el campo, como ocurre en Vida nueva del chileno Emilio Rodríguez Mendoza, y en Claudio Oronoz de Rubén M. Cam$\operatorname{pos}^{27}$. Solamente en las novelas de Enrique Gómez Carrillo se observa una tendencia hacia la neutralización del contraste entre el medio ambiente hostil (bastante reducido en este autor) y las aspiraciones de los protagonistas.

Para marcar su discrepancia con el medio ambiente, el héroe modernista demuestra un anhelo de vanguardismo artístico. Coincide en ello con el protagonista de la novela del fin de siglo europeo. Este anhelo, por manifestarse en una sociedad juzgada culturalmente todavía menos preparada que la europea, a pesar de tantas señales de modernidad que ya deja ver, tiende a justificarse todavía más que en su punto de origen. He aquí el momento en que la situación del héroe novelístico se une a la condición real del artista modernista en su tiempo.

Conocemos las proporciones de rechazo con las cuales tuvo que enfrentarse el intento del artista modernista de corresponder, según su concepción, a la modernidad de la época. He aquí también la razón por la que algunos de los héroes de novela, como José Fernández en De sobremesa, o Tulio Arcos en Sangre patricia (y otros menores como Carlos Lagrange en La tristeza voluptuosa de Dominici) quieren acelerar el desarrollo económico y social de su patria ${ }^{28}$. Traducen de este modo el deseo del autor modernista de intervenir en el proceso de transformación social, para conseguir un público más vasto y más idóneo. En última instancia vemos en ello un reflejo de la situación material del escritor latinoamericano, situación todavía de menor estabilidad que en la época actual. En algunos casos de esta intervención en el nivel del mundo novelístico se nota una tendencia acusada hacia el cesarismo, que podría escandalizar. Esta tendencia es obra de la influencia difusa de los escritos de Nietzsche (de un Nietzsche generalmente mal digerido) que, principalmente por medio de la divulgación francesa, llega también a Latinoamérica $^{29}$. Sabemos, para citar este solo ejemplo, que José Asunción Silva conoció algo de Nietzsche por sus conversaciones con Baldomero

26 D'Annunzio terminó la novela Le Vergini delle Rocce en 1895. Se publicó en versión francesa en 1896; cf. G. Gullace, D'Annunzio in France. A study in cultural relations, Syracuse, 1966, pp. 28 ss.

27 Cf. Emilio Rodríguez Mendoza, Vida nueva, Santiago (Chile), 1902; Rubén M. Campos, Claudio Oronoz, México, 1906; véase S.I. Zaḯzzeff, "Más sobre la novela modernista: Claudio Oronoz de Rubén M. Campos", ALH, (1976), 371-378

${ }^{28}$ Acerca de ios proyectos de Julio Fernández para cambiar la situación económica y político-social de su país, cf. mi trabajo Der spanischamerikanische Roman "des fin de siècle", ed. cit., pp. 58 ss.

29 Sobre Nietzsche en el mundo hispánico, cf. los trabajos de Udo Rukser, Nietzsche in der Hispania. Ein Beitrag zur hispanischen Kultur und Geistesgeschichte, Francke Verl., Bern-München, 1962, y Gonzalo Sobejano, Nietzsche en España, Gredos, Madrid, 1967 (BRH, 102). 
Sanín Cano ${ }^{30}$. En De sobremesa hay reflejos más bien desconcertantes del conocimiento que Silva tenía del filósofo alemán. En realidad, este cesarismo escandaloso no sale del marco de los demás componentes del vanguardismo que ostentan los protagonistas de la novela modernista. Corre parejas con una cierta predilección estética por las manifestaciones del anarquismo. Pero ofrece también un punto de partida para una cierta evolución de la literatura finisecular que se realizará bajo las diferentes versiones del régimen fascista.

Hay autores en Latinoamérica que prestarán un servicio al cesarismo político. Es el caso de Díaz Rodríguez y, por lo menos temporalmente, de Leopoldo Lugones. Lo es también de la mayoría de los modernistas mexicanos en el momento del golpe de estado del general Huerta ${ }^{31}$. Hay otros, como Vargas Vila, que combaten el cesarismo de hecho, aunque literariamente resultan de la misma estimp ${ }^{32}$. En su totalidad, la evolución de una parte del modernismo hacia el apoyo de soluciones autoritarias pertenece ya a una etapa ulterior del movimiento. Pero hay antecedentes en De sobremesa o, en el campo de la lírica, en Marcha triunfal, que se remontan a la última década del siglo xIX. Lugones, sin ser propiamente un novelista, anuncia desde 1905 un cambio de la fórmula novelística finisecular. En La guerra gaucha abandona la figura del protagonista finisecular como personaje de excepción a favor de un héroe anónimo, el gauchaje ${ }^{33}$. Pero al mismo tiempo hay en esta serie de episodios que es La guerra gaucha una nota de cesarismo. Se declara en la glorificación final del general Güemes ${ }^{34}$.

El viraje del vanguardismo literario y cultural del primer fin de siglo hacia el cesarismo se observa sobre todo en autores europeos como D'Annunzio y Barrès, tanto en sus obras como en sus declaraciones públicas. Es una consecuencia del sentimiento de condena individualista de la sociedad burguesa que experimenta el escritor marginado. A diferencia de los que vuelven la espalda a la sociedad, los partidarios del cesarismo quieren dominarla por el terror. Pero sería erróneo concluir que tanto el fin de siglo europeo como el modernismo conducen de por sí al apoyo del autoritarismo político. Hay otras soluciones, como por ejemplo la reconciliación con la doctrina cristiana, que reemplazan al vanguardismo artístico ofensivo. Son soluciones que se preconizan en las

${ }^{30}$ Acerca del papel de Sanín Cano en la historia del modernismo en Colombia, cf. P. González-Rojas, "Orígenes del modernismo en Colombia: Sanín Cano, Silva, Darío", CuH, 1972, núm. 268, 62-92.

31 Cf. Jost́ EmLlo Pacheco (ed.), Antología del modernismo, UNAM, México, 1970 , t. 1, p. L.

32 VARGaS VILA fulmina contra los caudillos colombianos y venezolanos de su época en su panfleto Los césares de la decadencia, Barcelona, s.f. A pesar de ello hay en los héroes de sus novelas una marcada estilización cesarista.

33 Cf. Leopoldo Lugones, La guerra gaucha, Buenos Aires, 1905 (ed. utilizada: $2^{\mathrm{a}}$ ed., Buenos Aires, 1926).

34 Ibid., pp. 267 ss. 
novelas del colombiano José M. Rivas Groot y de Ángel de Estrada ${ }^{35}$. La concentración del argumento a favor del protagonista que, en el plano de la expresión, se observa en la novela modernista, es consecuencia del interés narrativo en las vicisitudes de la "vida interior" que marca el principio del fin de siglo europeo. Cuando pensamos en $\dot{A}$ rebours de Huysmans, o en Sixtine de Rémy de Gourmont, nos damos cuenta del papel importante que tiene la introspección en aquellas novelas. El fin de siglo, y hasta sus partidarios más superficiales como Bourget, proclamaban el examen del alma humana. Lo proclamaban para oponerse a la exigencia del naturalismo de representar el mundo exterior y sus miserias (en la perspectiva de Zola, para superarlas). En Hispanoamérica siguen el ejemplo de la introspección algunas novelas modernistas como De sobremesa o El extraño. Lo sigue también la novela La raza de Caín de Reyles, a pesar de la condena de la introspección que propone el autor. La conversión al vitalismo, que Reyles preconiza a partir de 1900 , no es sino la otra cara de la medalla del tedio finisecular. Notamos el surgimiento del vitalismo, o sea "la volición viril", como la llama Reyles, en la obra de D'Annunzio, para sólo citar un ejemplo, después de la publicación de Trionfo della morte en $1894^{36}$.

La concentración del argumento a favor del protagonista novelístico corre parejas con la reducción de la acción, o sea el abandono de la intriga complicada, llena de peripecias. Se trata de una herencia del realismo en la concepción que le dio Flaubert. Esta reducción se manifiesta en muchos de sus discípulos, como se puede observar recordando las novelas de Clarín o de Eça de Queiroz. La mayoría de las novelas modernistas hispanoamericanas continúa con esta tradición. Sin embargo, hay ejemplos, como las novelas de Vargas Vila, que vuelven a la intriga inverosímil, llena de acción ${ }^{37}$. Es probable que aquí se trate de la influencia de una corriente especial del fin de siglo francés, representada por las novelas de Péladan y Mme. Rachilde ${ }^{38}$. En su conjunto, Vargas Vila no se une sino parcialmente a la narrativa modernista hispanoamericana. Pertenece más bien a un romanticismo tardío que deja también su huella en las vicisitudes de la acción de La gloria de don Ramiro ${ }^{39}$.

35 Cf. José M. Rivas Groot, Resurrección, Bogotá, 1901 (ed. utilizada: París, 1912); El triunfo de la vida, Madrid, 1916; y, especialmente, ÁNGEL DE ESTRADA, Redención, Buenos Aires, 1906.

${ }^{36}$ El fruto más visible de esta conversión al vitalismo de ReYLES es el ensayo La muerte del cisne, París, s.f. (1910).

${ }^{37}$ La bibliografía de VARGAS VILA queda por hacer. La primera novela proclamada artística del autor es Ibis, Roma, 1900 (ed. utilizada: París, 1908).

${ }^{38}$ Péladdan es el autor del ciclo novelístico La décadence latine. Ethopéé, Paris, 18841924. Mme. Rachilde (i.e., Marguerite Vallette) era la esposa de Alfred Vallette, el editor del Mercure de France. Escribió una serie de novelas eróticas, bastante discutidas durante el fin de siglo. Darío la cuenta entre los "raros", cf. Obras completas, Madrid, 1950-1955, t. 2, pp. 365 ss.

${ }^{39}$ Acerca de la influencia del romanticismo en La gloria de don Ramiro, cf. A. 
Para describir las sensaciones de sus personajes, el escritor modernista se sirve frecuentemente del estilo indirecto libre. Este procedimiento especial de reproducción del discurso de los personajes ofrece la ventaja de un cambio de la perspectiva en el nivel del narrador, que hace desaparecer el punto de vista de éste a favor del personaje narrado. Permite además incorporar algunos elementos típicos del estilo directo oral en el discurso narrativo, sin poner de relieve la figura y función del narrador. Fueron flaubert y sus discípulos quienes, por primera vez en la novela, desarrollaron este procedimiento estilístico de manera sistemática. Por lo tanto, se encuentra también en la novela naturalista. Pero, en realidad, se presta mejor a las exigencias de la novela finisecular con su enfoque particular sobre el protagonista de la acción. A veces, el novelista modernista abandona por completo el esquema de la narración en tercera persona (y, de ahí, la persona del narrador independiente). Recurre a los procedimientos de la narración desde el punto de vista de un "yo", que ofrecen mayores posibilidades de introspección. Así encontramos en el modernismo con De sobremesa la novela en forma de diario íntimo o, en el caso del peruano A. Carrillo (Cabotín), la tradicional novela epistolar ${ }^{40}$. Por lo que al monólogo interior se refiere, el modernismo todavía lo desconoce. Pero ya había sido desarrollado para los mismos fines artísticos por el escritor finisecular francés Édouard Dujardin.

En algunos de los representantes de la novela modernista hispanoamericana hay señales que anuncian una independización del nivel lingüístico de expresión. En estos casos, la novela modernista parece unirse a las preocupaciones de los partidarios de la "poetización" de la prosa literaria, o sea de la preponderancia de la función poética del lenguaje en la literatura. Esta preponderancia será llevada a sus consecuencias más audaces por algunos simbolistas franceses de la época, especialmente Mallarmé. Pero hay que reconocer que la novela, probablemente también por las exigencias de sus leyes específicas, se muestra mucho más tibia en este terreno que los demás géneros literarios del fin de siglo.

Como los demás géneros literarios cultivados por el modernismo, la novela, con el fin de establecer un paralelo lingüístico a la ostentación del vanguardismo literario, artístico o cultural del protagonista, participa en el intento de renovar el lenguaje literario. En su conjunto, es difícil determinar la parte exacta que le corresponde a la novela modernista dentro de esta operación. Se necesitaría un vasto estudio de conjunto de toda la prosa del modernismo para poder resolver la cuestión. Sin embargo, gracias a los trabajos ya realizados se pueden adelantar algunas conclusiones.

Se nota un afán, aunque no siempre sostenido, de buscar el término

Alonso, op. cit., pp. 158 ss., así como A. JANSEn, op. cit., pp. 86 ss. En la novela de Larreta hay también una influencia de la novela picaresca española.

40 Cf. Enrique A. Carrillo (Cabotín), Cartas de una turista, Lima, 1905 (ed. utilizada: Lima, 1959). 
léxico más apropiado para la representación y la connotación de los sentimientos, sensaciones y actitudes del protagonista de la novela. En última instancia se trata de la continuación del esfuerzo estilístico que ya exigía la teoría de la novela naturalista. La diferencia reside en el objeto del esfuerzo. Mientras el escritor naturalista buscaba el término justo para la representación del mundo cotidiano, el escritor finisecular desecha este mundo como objeto del interés novelístico y favorece la representación de un mundo depurado de lo cotidiano o francamente "interior". Ambos coinciden, sin embargo, en que la vieja tradición estilística heredada del romanticismo y el costumbrismo español ya no bastaba para satisfacer las nuevas necesidades de expresión. Esta tradición no sólo falla en el terreno del léxico, sino también en el de la sintaxis.

Quiero terminar esta yistón panorámicacon algunas observaciones sobre los comienzos de la novela modernista en Hispanoamérica. Desde la publicación del trabajo pionero de Anderson Imbert sobre Amistad funesta de Martít ${ }^{41}$, solemos considerar la obra del cubano como la primera novela del modemismo hispanoamericano. A mi modo de ver, esta calificación se justifica solamente en parte. Es sabido que Martí escribió Amistad funesta para un público lector que estaba acostumbrado a cierto género de novelas románticas. Había recibido la comisión de escribirla gracias a Adelaida Baralt, otra cubana exilada de la colonia hispanoamericana de Nueva York ${ }^{42}$. Martí tuvo que atenerse al gusto de sus lectores. Así lo confiesa en el borrador del prólogo para la edición en forma de libro de la obra, el cual se conservó ${ }^{43}$. Podemos afirmar que Martí supo corresponder brillantemente a la expectativa de su público y de sus editores. Pero no cabe duda que le atribuyó un pequeño valor literario a su "noveluca" 44 . Según Martí, Amistad funesto no pertenece a la corriente de la novela moderna que califica de "profunda como un bisturí y útil como un médico". Entra más bien en el grupo de novelas "de puro cuento, en las que no es dado tender a nada serio". Desgraciadamente, no conocemos la fecha del borrador martiano. Lo debe haber compuesto alrededor de $1890^{45}$. Es obvio que Martí opone Amistad funesta a la novela moderna que, para él, dado las

41 Cf. E. Anderson Imbert, "La prosa poética de José Martí. A propósito de Amistad funesta", en Memoria del Congreso de Escritores Martianos, La Habana, 1953, pp. 570-616 (también en ENRIQUE ANDERson IMBERT, Estudios sobre escritores de América, Buenos Aires, 1954, pp. 125-165).

${ }^{42}$ Acerca de la génesis de Amistad funesta, cf. La introducción en José MarTí, Lucía Jerez, ed. M. P. González, Madrid, 1969, pp. 32 ss.

${ }^{43} \mathrm{El}$ borrador está reproducido en la ed. cit. de M. P. González, ibid., pp. 36 s. Dice Martí al respecto: "Yo quiero ver al valiente que saca de los [ . . .] una novela buena. En la novela había de haber mucho amor; alguna muerte; muchas muchachas; ninguna pasión pecaminosa; y nada que no fuese del mayor agrado de los padres de familia y de los señores sacerdotes. Y había de ser hispanoamericana” (ibid., p. 37).

44 Dice Martí: "Quien ha escrito esta noveluca, jamás había escrito otra antes" (ibid., p. 36).

45 Cf. ibid., pp. 35 s. 
calificaciones que emplea, parece ser la novela naturalista. Pide excusas por el atraso de su obra desde el punto de vista de la evolución literaria. Pero.no le gusta el género novelístico, y tampoco le gusta el naturalismo ${ }^{46}$. No obstante, en el mismo borrador declara que "ha procurado hacerse perdonar con algunos detalles"'. Estos detalles parecen ser aquellos elementos estilísticos que hicieron de Martí uno de los iniciadores del modernismo. Parecen ser también, en el nivel del contenido novelístico, las descripciones de las habitaciones en la casa de Lucía Jerez, que lo relacionan con las novelas del fin de siglo europeo. Por sus vastos conocimientos y su labor de crítico, Martí estaba al tanto de la evolución literaria, la cual, incluso, juzgaba de manera muy independiente. Pero su novela no deja de ser un ejemplo más del romanticismo hispanoamericano. Así lo piensa también, por lo menos en la primera presentación de su trabajo, el propio Anderson Imbert.

Más interesante es el caso de la novela Sin rumbo de Eugenio Cambaceres. Se publica en el mismo año de 1885 en el que aparece Amistad funesta $^{47}$. El autor la presenta según la orientación naturalista. En realidad, resulta una novela modernista aüani la lettre o, para precisar, una novela del primer modernismo. Muestra la reducción del argumento a favor del protagonista con el enfoque particular sobre la vida "interior". Muestra la oposición característica de la novela finisecular entre el sistema de valores del protagonista y su medio ambiente. Muestra cierto vanguardismo, aunque más abiertamente ideológico que artístico, en la predilección del protagonista por la filosofía de Schopenhauer. Finalmente, comprueba la voluntad del novelista de crear un nivel de expresión literaria que corresponda a las intenciones del argumento. Mientras Martí, por las limitaciones de la comisión que le ha sido confiada, y tal vez también a causa de su propio menosprecio hacia el género novelístico, no sale del marco del romanticismo, Cambaceres logra rebasar, sin tener conciencia de ello, la orientación naturalista. Presenta una obra que, a la luz de la evolución ulterior, resulta la primera representante de la novela modernista en Hispanoamérica. Cambaceres no pudo darse cuenta del alcance de su realización artística. Murió antes de la autoproclamación ruidosa del modernismo. En su última novela, En la sangre, vuelve a la fórmula naturalista que, a diferencia de la obra anterior, lo hace prisionero de la orientación escogida ${ }^{48}$.

A pesar de Martí y de Cambaceres, la novela modernista hispanoamericana sólo llega a la conciencia de sí misma con El bachiller de Amado

${ }^{46}$ MARTí parece haber conocido bastante bien la novela naturalista francesa. Hay varias alusiones al naturalismo en su obra, especialmente en la serie de Escenas europeas (en Obras completas, La Habana, 1963-1966, t. 14; cf. también Europa. Crítica y arte, t. 15).

47 Cf. Eugenio Cambaceres, Sin rumbo, Buenos Aires, 1885 (ed. utilizada: Sin rumbo, ed. T. Frugoni de Fritzsche, $2^{\text {a }}$ ed., Buenos Aires, 1968).

${ }^{48} \mathrm{Cf}$. al respecto mi trabajo Sinngebung, Erzählweise und die geschichtliche Wirklichkeit bei Eugenio Cambaceres, en HHKS, pp. 465-495, y J. EPPLE, Eugenio Cambaceres y el naturalismo en Argentina, I\&L, 3 (1980), núm. 14, 16-46. 
Nervo y Pasiones de José Gil Fortoul, ambas publicadas en $1895^{49}$, así como, de manera cabal, con De sobremesa. Se proclama "novela nueva", es decir novela moderna, o del modernismo, cuando la polémica sobre El extraño entre Juan Valera y Carlos Reyles ${ }^{50}$. Algunos meses antes, José Enrique Rodó había publicado su ensayo sobre la novela de Rey* les, el cual consagró definitivamente a la novela modernista como modelo para la vanguardia literaria americana ${ }^{51}$.

KLAUS MEYer-MinNemanN

Universität Hamburg.

49 Cf. Amado Nervo, "El bachiller", novela corta, México, 1895; José Gil ForTOUL, Pasiones, París, 1895.

${ }^{50}$ Acerca de esta polémica, cf. E. S. MORsy, "Una batalla entre antiguos y modernos. Juan Valera y Carlos Reyles", RevIb, 4 (1941-42), 119-143, y mi trabajo Der spanischamerikanische Roman "des fin de siècle", ed. cit., pp. 95 ss.

${ }^{51}$ Cf. José EnRiQue Rodó, La Vida Nueva I (El que vendrá; La novela nueva), Montevideo, 1897 (ed. utilizada: Obras completas, ed. E. Rodríguez Monegal, $2^{\text {a }}$ ed., Madrid, 1973, pp. 149-164). 